\title{
A population-based study examining the influence of a specialized rapid-access cancer clinic on initial treatment choice in localized prostate cancer
}

\author{
Larissa J. Vos ${ }^{1}$; Clement K. Ho ${ }^{2,3}$; Bryan J. Donnelly ${ }^{2,4}$; J. Dean Reuther ${ }^{2,3}$; Marc Kerba ${ }^{2,3}$ \\ ${ }^{1}$ Alberta Cancer Clinical Trials, Cross Cancer Institute, Edmonton, AB; ${ }^{2}$ University of Calgary, Calgary, AB; ${ }^{3}$ Tom \\ Baker Cancer Centre, Calgary, AB; ${ }^{4}$ Prostate Cancer Centre, Calgary, AB; Canada
}

Cite as: Can Urol Assoc J 2018 March 19; Epub ahead of print. http://dx.doi.org/10.5489/cuaj.4866

Published online March 19, 2018

***

\section{Abstract}

Introduction: Treatment decisions in localized prostate cancer are complicated by the available choices. A rapid-access cancer clinic (RAC) has been unique to Calgary, AB, since 2007. This RAC offers multidisciplinary prostate cancer education by a urologist, medical oncologist, and radiation oncologist. It is hypothesized that treatment utilization data from decisions taken at RAC may serve to benchmark the appropriateness of treatment decisions on a population level. Methods: Records of patients with clinically localized prostate cancer in Alberta between October 1, 2007 and September 30, 2009 were reviewed with ethics approval. Records were linked to the Alberta Cancer Registry database. Clinical, treatment, and health services characteristics pertaining to patients attending RAC were compared to the general population. The primary endpoint was utilization rates of each initial treatment.

Results: During this two-year period, 2838 patients were diagnosed with localized prostate cancer; 375 attended RAC. The utilization rates among RAC patients vs. the whole Alberta population were: prostatectomy 60.3\% (95\% confidence interval [CI] 55.3-65.2) vs. 48.0\% (95\% CI 47.1-50.7; $\chi^{2} \mathrm{p}<0.001$ ); active surveillance $16.0 \%$ (95\% CI 12.3-19.7\%) vs. 13.5\% (95\% CI 12.2-15.8; $\left.\chi^{2} \mathrm{p}=0.214\right)$; radiotherapy $11.7 \%$ (95\% CI 8.5-15.0) vs. $18.0 \%$ (95\% CI 16.9-20.5; $\chi^{2}$ $\mathrm{p}=0.002)$; and hormone therapy $8.0 \%$ (95\% CI 5.2-10.8) vs. $17.4 \%$ (95\% CI 16.1-18.9; $\left.\chi^{2} \mathrm{p}<0.001\right)$.

Conclusions: A specialized clinic for localized prostate cancer may be associated with a higher likelihood of receiving surgery or active surveillance as initial treatment compared to the prostate cancer population in Alberta. 


\section{Introduction}

Prostate cancer is the most common non-dermatological cancer among men in developed countries and the third leading cause of cancer-related mortality. ${ }^{1}$ Improved techniques and screening for prostate specific antigen (PSA) have led to earlier detection and increased incidence of low and intermediate risk disease. ${ }^{2}$ There are numerous treatment options available for low and intermediate risk prostate cancer including active surveillance, radiation therapy (RT) (external beam or brachytherapy), hormone therapy, and surgery (radical prostatectomy). ${ }^{3}$ Each of these treatment options has their own risks and benefits.

The majority of prostate cancer diagnoses are made through tests requested by the primary care provider with subsequent treatment choice influenced by the type of specialist at first contact following referral. ${ }^{4,5}$ Treatment decisions are also known to be influenced by "subjective” factors such as patient fear of surgery/radiation, concern over disease progression if untreated, perceived "best” treatment, and different priorities of treatment benefits and risks (e.g. sexual dysfunction). ${ }^{6}$ Therefore a considered approach to choosing the appropriate therapy for each patient requires balancing patient and disease characteristics (age, comorbidities and Gleason score), life expectancy, and patient preference. ${ }^{3}$

A rapid access cancer clinic (RAC) has been operating in Calgary, Alberta since 2007 and offers multidisciplinary prostate cancer education to patients and their partners from an urologist, a medical oncologist, and a radiation oncologist in an evening session. The RAC conducts education sessions that aim to provide information on treatment options and allow for patients to engage with specialists so they are able to make an educated decision in discussion with their physician. It is hypothesized that treatment utilization data from decisions taken at RAC may serve to benchmark the appropriateness of treatment decisions on a population level.

\section{Methods}

\section{Study population}

This retrospective study examined the initial treatment received by Alberta patients with low or intermediate risk localized prostate cancer between October 1, 2007 and September 30, 2009 and an overlapping patient cohort with low risk localized prostate cancer diagnosed in 2007. Low or intermediate risk prostate cancer was defined as tumours stage T1 or T2, Gleason score $\leq 7$, and

PSA $\leq 20 \mathrm{ng} / \mathrm{mL}^{7}$ This time period was selected for the cleanliness of data as it was prior to expansion of treatment through a "radiation corridor" in Alberta. The 2 centralized and tertiary cancer centres would allow for a benchmark rate of RT utilization to be examined.

Source of data

This study was granted local Research Ethics Board approval to access patient charts and health records. The Alberta Cancer Registry records and maintains data on all new cancer cases and cancer deaths occurring in the province, whose data is known to be of very high quality and covers the entire Alberta population. ${ }^{8}$ The Registry provides information on the date of diagnosis, collaborative stage, type and date of treatment, as well as personal information, such 
as date of birth, gender, provincial health care number, and postal code. Radiotherapy information from cancer centres in Alberta was electronically linked to the Alberta Cancer Registry. Patients' driving distances from residence to the cancer centres were calculated by entering each postal code at diagnosis and the postal code of the closest cancer centre, either the Cross Cancer Institute or the Tom Baker Cancer Centre, into Google Maps. All male adults aged over 18 diagnosed with localized prostate cancer between October 1, 2007 and September 30, 2009, residing in Alberta, Canada, and registered in the Alberta Cancer Registry were eligible for analysis.

\section{Statistics}

Descriptive statistics were calculated for the study variables and frequencies and percentages are reported. Clinical, treatment, and health service characteristics pertaining to patients attending RAC were compared to those managed elsewhere in Alberta. The categorical variables were compared between the two groups using chi-square tests. The primary endpoint was utilization rates of initial treatment. A p-value $<0.05$ was used for all statistical significance. All statistical analyses were performed using SAS (version 9.1).

\section{Results}

\section{Patient characteristics}

Between October 1, 2007 and September 30, 2009, 2838 men were diagnosed with low or intermediate risk localized prostate cancer and were evaluable for this analysis. Of these, 375 patients attended a RAC education session. There were 1903 men with low risk localized prostate cancer treated in 2007. Of these, 22 patients attended a RAC education session. The highest proportion of patients in Alberta and the RAC subpopulation were between 60 and 69 years of age (Table 1). There was a statistically significant trend towards younger patients attending a RAC session. The time and distance from cancer treatment centre was significantly shorter for patients attending RAC compared to the general Alberta population. The income distribution was similar in the Alberta patients and the RAC subgroup.

\section{Initial treatment}

The most frequently utilized treatment for patients diagnosed between October 1, 2007 and September 30, 2009 in Alberta was surgery 48.0\% (95\% CI: 46.2-49.9) (Table 2). In the general Alberta localized prostate cancer patient population the next most frequent treatments used were radiotherapy 18.0\% (95\% CI: 16.7-19.5), hormone therapy 17.4\% (95\% CI: 16.0-18.8), and active surveillance 13.5\% (95\% CI: 12.3-14.8). This treatment frequency was different for patients that attended RAC ( $\left.\chi^{2} \mathrm{p}=0.013\right)$. A higher proportion of patients had surgery $60.3 \%$, (95\% CI: 55.2-65.1) while active surveillance 16.0\% (95\% CI: 12.6-20.1), radiotherapy 11.7\% (95\% CI: 8.9-15.4) and hormone therapy 8.0\% (95\% CI: 5.7-11.2) use were either similar or lower. Among patients that received radiotherapy there was a shift towards increased brachytherapy for patients that attended RAC $\left(\chi^{2} \mathrm{p}=0.002\right)$. In the low risk localized prostate 
cancer population surgery was still the most utilized first treatment but the rate was lower and similar between the whole Alberta population (35.8\%; 95\% CI: 33.7-38.0) and those that attended RAC (36.4\%; 95\% CI: 19.7-57.0). Similar to the low and intermediate combined population, the patients that attended RAC were less likely to receive radiotherapy or hormone therapy than the general Alberta patient population. There was a substantial increase in active surveillance among patients that attended RAC (27.3\%; 95\% CI: 13.2-48.2) compared with the general Alberta population with low risk localized prostate cancer (15.6\%; 95\% CI: 14.0-17.3).

\section{Discussion}

There are numerous available and effective treatments for low and intermediate risk localized prostate cancer. ${ }^{3}$ Many factors influence which treatment is utilized for each patient including patient age, comorbidities, disease characteristics (e.g. Gleason score), and patient preference. ${ }^{9-13}$ The initial point of contact with the health system is also important.

The proportion of patients that received surgery was higher in the combined low and intermediate risk subpopulation of patients that attended RAC. This was influenced by the lower age distribution for patients that attended RAC, (as radical prostatectomy is generally not recommended for men $>70$ years of age ${ }^{14}$ ) compared to standard "sequential based practice" of presentation to a urologist followed by possible referral to a cancer centre. Among the patients that had radiotherapy as the first treatment there was an increased probability of choosing brachytherapy for localized prostate cancer if the patient attended RAC. Active surveillance was also slightly higher in the subgroup of patients that attended RAC. It is understood that an inherent selection bias exists in a best practice clinic, in that the characteristics of the population under study influences the treatment options available to them. For RAC the population was younger and had closer proximity to a major cancer centre, but their socioeconomic status was no different from the rest of the prostate cancer population. We postulate that the information services provided at the RAC education sessions are consistent with best practice. Treatment decisions made by patients after participating in the session were likely mediated by alleviating cancer information concerns around treatment efficacy and side-effects.

A survey of 262 men with localized prostate cancer treated with either radical prostatectomy $(n=81)$ or brachytherapy $(n=167)$ revealed that regardless of treatment the source of greatest information was the urologist followed by the internet. ${ }^{15}$ When asked what factors influenced their treatment decision the majority of patients made their treatment choice based on the belief that it gave the best chance of curing their cancer. For men that received radical prostatectomy this was the main criterion of treatment choice ( $97.5 \%$ of patients). For men that received brachytherapy the treatment effectiveness was most important for $49.1 \%$ of patients while side-effect profile was also listed as highly influential for treatment decisions (main criterion in $34.7 \%$ of patients). ${ }^{15}$

The utilization rate of radiotherapy in Alberta is low and even lower in patients that attended RAC. A Canadian study of radiotherapy utilization estimated that for patients with low risk prostate cancer $21.9 \%$ would have radiotherapy as first treatment and that this proportion 
would increase to $34.5 \%$ of patients with intermediate risk prostate cancer. ${ }^{9,10}$ One of the reasons for the low radiotherapy utilization observed in Alberta may be because of the travel time associated with attending tertiary cancer centres. Studies have shown that likelihood of receiving radiotherapy decreases with increased travel time. ${ }^{11}$ This effect will be addressed in the near future with the expansion of radiotherapy capacity from 2 to 5 radiotherapy centres allowing for $90 \%$ of patients to receive RT treatment within $100 \mathrm{~km}$ of home.

Interestingly this study has shown that when providing access to a radiation oncologist, as provided in the RAC sessions, the observed radiotherapy rates are actually lower than expected. This is unlikely a result of different clinical outcomes as surgery and radiotherapy for intermediate risk prostate cancer have similar short-term survival benefits ${ }^{16}$ although it may be a function of the RAC population characteristics, including lower age. The higher proportion of patients that received surgery is not a clinically meaningful difference but has a substantial impact on health system resource utilization. It may be that in the context of benchmarking appropriate radiotherapy or treatment rates in general that the availability and accessibility of comparative information on treatment choices represents an unmet patient need. Not addressing such gaps in care may lead to population level consequences involving health system resource allocation and patient outcomes. 


\section{References}

1. Canadian Cancer Society. Canadian Cancer Statistics 2017. [cited July 5 2017. http://www.cancer.ca/ /media/cancer.ca/CW/publications/Canadian\%20Cancer\%20 Statistics/Canadian-Cancer-Statistics-2017-EN.pdf. Accessed June 282017.

2. Neppl-Huber C, Zappa M, Coebergh JW, et al: Changes in incidence, survival and mortality of prostate cancer in Europe and the United States in the PSA era: additional diagnoses and avoided deaths. Ann Oncol 2012;23:1325-34.

3. Keyes M, Crook J, Morton G, Vigneault E, Usmani N, Morris WJ: Treatment options for localized prostate cancer. Can Fam Physician 2013;59:1269-74.

4. Fowler FJ, Jr., McNaughton Collins M, Albertsen PC, Zietman A, Elliott DB, Barry MJ: Comparison of recommendations by urologists and radiation oncologists for treatment of clinically localized prostate cancer. JAMA 2000;283:3217-22.

5. Sommers BD, Beard CJ, D'Amico AV, Kaplan I, Richie JP, Zeckhauser RJ: Predictors of patient preferences and treatment choices for localized prostate cancer. Cancer 2008;113:2058-67.

6. Showalter TN, Mishra MV, Bridges JF: Factors that influence patient preferences for prostate cancer management options: A systematic review. Patient Prefer Adherence 2015;9:899-911.

7. NCCN Clinical Practice Guidelines in Oncology (NCCN Guideline): Prostate Cancer, National Comprehensive Cancer Network, 2014

8. International Association of Cancer Registries. Alberta Cancer Registry Profile Page. [cited July 5

2017]. http://www.iacr.com.fr/index.php?option=com_comprofiler\&task=userprofile\&user $=887 \&$ Itemid=498. Accessed June 282017.

9. Delaney G, Jacob S, Barton M: Estimating the optimal external-beam radiotherapy utilization rate for genitourinary malignancies. Cancer 2005;103:462-73.

10. Foroudi F, Tyldesley S, Barbera L, Huang J, Mackillop WJ: Evidence-based estimate of appropriate radiotherapy utilization rate for prostate cancer. Int J Radiat Oncol Biol Phys 2003;55:51-63.

11. Jones AP, Haynes R, Sauerzapf V, Crawford SM, Zhao H, Forman D: Travel time to hospital and treatment for breast, colon, rectum, lung, ovary and prostate cancer. Eur $J$ Cancer 2008;44:992-9.

12. Kerba M, Miao Q, Zhang-Salomons J, Mackillop W: Defining the need for prostate cancer radiotherapy in the general population: a criterion-based benchmarking approach. Clin Oncol (R Coll Radiol) 2010;22:801-9.

13. Shack L, Lu S, Weeks LA, Craighead P, Kerba M: Determining the need and utilization of radiotherapy in cancers of the breast, cervix, lung, prostate and rectum: A population level study. Radiother Oncol 2017;122:152-8.

14. Lepor H: Selecting candidates for radical prostatectomy. Rev Urol 2000;2:182-9. 
15. Hall JD, Boyd JC, Lippert MC, Theodorescu D: Why patients choose prostatectomy or brachytherapy for localized prostate cancer: results of a descriptive survey. Urology 2003;61:402-7.

16. Klein EA, Ciezki J, Kupelian PA, Mahadevan A: Outcomes for intermediate risk prostate cancer: are there advantages for surgery, external radiation, or brachytherapy? Urol Oncol 2009;27:67-71. 
Figures and Tables

Table 1. Characteristics of patients diagnosed from Oct.1, 2007 to Sept. 30, 2009

\begin{tabular}{|c|c|c|c|c|c|}
\hline & $\begin{array}{c}\text { Total } \\
\text { patients } \\
\text { diagnosed in } \\
\text { Alberta } \\
(\mathbf{n}=\mathbf{2 8 3 8})\end{array}$ & $\begin{array}{c}95 \% \\
\text { confidence } \\
\text { Interval }\end{array}$ & $\begin{array}{c}\text { Subpopulation } \\
\text { patients seen at } \\
\text { RAC (n=375) }\end{array}$ & $\begin{array}{c}95 \% \\
\text { confidence } \\
\text { Interval }\end{array}$ & $\begin{array}{l}\chi^{2} \\
\mathbf{p}\end{array}$ \\
\hline Characteristic & n (\%) & n (\%) & n (\%) & n (\%) & \\
\hline Age group & & & 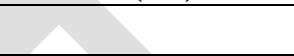 & & 0.0017 \\
\hline $18-49$ & $111(3.9)$ & $\begin{array}{c}93-133 \\
(3.3-4.7)\end{array}$ & $27(7.2)$ & $\begin{array}{c}19-39 \\
(5.0-10.3) \\
\end{array}$ & \\
\hline $50-59$ & 705 (24.8) & $\begin{array}{c}661-751 \\
(23.3-26.5) \\
\end{array}$ & $131(34.9)$ & $\begin{array}{c}114-150 \\
(30.3-39.9)\end{array}$ & \\
\hline $60-69$ & 1123 (39.6) & $\begin{array}{l}1072-1174 \\
(37.8-41.4)\end{array}$ & $163(43.5)$ & $\begin{array}{c}145-182 \\
(38.5-48.5)\end{array}$ & \\
\hline $70-79$ & 745 (26.3) & $\begin{array}{c}700-792 \\
(24.7-27.9)\end{array}$ & $51(13.6)$ & $\begin{array}{c}39-65 \\
(10.5-17.4)\end{array}$ & \\
\hline $80+$ & $154(5.4)$ & $\begin{array}{l}132-180 \\
(4.7-6.3) \\
\end{array}$ & $3(0.8)$ & $\begin{array}{c}1-9 \\
(0.3-2.3)\end{array}$ & \\
\hline Zone within Alberta & & 2 & Y & & $<0.0001$ \\
\hline South & $215(7.6)$ & $\begin{array}{l}189-244 \\
(6.7-8.6) \\
\end{array}$ & $3(0.8)$ & $\begin{array}{c}1-9 \\
(0.3-2.3) \\
\end{array}$ & \\
\hline Calgary & $1021(36.0)$ & $\begin{array}{c}971-1072 \\
(34.2-37.8) \\
\end{array}$ & $368(98.1)$ & $\begin{array}{c}361-372 \\
(96.2-99.1) \\
\end{array}$ & \\
\hline Central & 352 (12.4) & $\begin{array}{c}319-388 \\
(11.2-13.7) \\
\end{array}$ & $4(1.1)$ & $\begin{array}{c}2-10 \\
(0.4-2.7) \\
\end{array}$ & \\
\hline Edmonton & 934 (32.9) & $\begin{array}{c}886-984 \\
(31.2-34.7) \\
\end{array}$ & $0(0.0)$ & $\begin{array}{c}0-4 \\
(0.0-1.0) \\
\end{array}$ & \\
\hline North & 316 (11.1) & $\begin{array}{c}258-350 \\
(10.0-12.3) \\
\end{array}$ & $0(0.0)$ & $\begin{array}{c}0-4 \\
(0.0-1.0) \\
\end{array}$ & \\
\hline $\begin{array}{l}\text { Distance to either } \\
\text { CCI or TBCC }\end{array}$ & & & & & $<0.0001$ \\
\hline$<50 \mathrm{~km}$ & $1770(62.4)$ & $\begin{array}{r}1719-1820 \\
(60.6-64.1) \\
\end{array}$ & 337 (89.9) & $\begin{array}{c}323-347 \\
(86.3-92.7) \\
\end{array}$ & \\
\hline $50-100 \mathrm{~km}$ & $295(10.4)$ & $\begin{array}{c}265-328 \\
(9.3-11.6) \\
\end{array}$ & $26(6.9)$ & $\begin{array}{c}18-37 \\
(4.8-10.0) \\
\end{array}$ & \\
\hline $100-200 \mathrm{~km}$ & $476(16.8)$ & $\begin{array}{c}438-516 \\
(15.4-18.2) \\
\end{array}$ & $2(0.5)$ & $\begin{array}{c}1-7 \\
(0.1-1.9) \\
\end{array}$ & \\
\hline $200+\mathrm{km}$ & 297 (10.5) & $\begin{array}{c}267-331 \\
(9.4-11.7)\end{array}$ & $10(2.7)$ & $\begin{array}{c}5-18 \\
(1.5-4.8)\end{array}$ & \\
\hline Income quintiles & & & & & 0.9925 \\
\hline
\end{tabular}




\begin{tabular}{|c|c|c|c|c|c|}
\hline Prefer not to reply & $87(3.1)$ & $\begin{array}{c}71-107 \\
(2.5-3.8)\end{array}$ & $16(4.3)$ & $\begin{array}{c}10-26 \\
(2.7-6.8)\end{array}$ & \\
\hline$<\$ 64175$ & $554(19.5)$ & $\begin{array}{c}514-597 \\
(18.1-21.0)\end{array}$ & $72(19.2)$ & $\begin{array}{c}58-88 \\
(15.5-23.5)\end{array}$ & \\
\hline$\$ 64175-78053$ & $548(19.3)$ & $\begin{array}{c}508-590 \\
(17.9-20.8)\end{array}$ & $72(19.2)$ & $\begin{array}{c}58-88 \\
(15.5-23.5)\end{array}$ & \\
\hline$\$ 78054-92384$ & $551(19.4)$ & $\begin{array}{c}511-594 \\
(18.0-20.9)\end{array}$ & $72(19.2)$ & $\begin{array}{c}58-88 \\
(15.5-23.5)\end{array}$ & \\
\hline$\$ 92385-119594$ & $549(19.3)$ & $\begin{array}{c}509-591 \\
(17.9-20.8)\end{array}$ & $72(19.2)$ & $\begin{array}{c}59-89 \\
(15.8-23.8)\end{array}$ & \\
\hline$\geq \$ 119595$ & $549(19.3)$ & $\begin{array}{c}509-591 \\
(17.9-20.8)\end{array}$ & $71(18.9)$ & $\begin{array}{c}57-88 \\
(15.2-23.3)\end{array}$ & \\
\hline
\end{tabular}


Table 2. Initial treatment of patients diagnosed from Oct.1, 2007 to Sept. 30, 2009

\begin{tabular}{|c|c|c|c|c|}
\hline & $\begin{array}{l}\text { Total patients } \\
\text { diagnosed in } \\
\text { Alberta } \\
(n=2838)\end{array}$ & $\begin{array}{c}95 \% \\
\text { confidence } \\
\text { Interval }\end{array}$ & $\begin{array}{l}\text { Subpopulation } \\
\text { seen at RAC } \\
(n=375)\end{array}$ & $\begin{array}{c}95 \% \\
\text { confidence } \\
\text { Interval }\end{array}$ \\
\hline & n (\%) & n (\%) & n (\%) & n (\%) \\
\hline Radiotherapy & $512(18.0)$ & $\begin{array}{c}473-553 \\
(16.7-19.5)\end{array}$ & $44(11.7)$ & $\begin{array}{c}33-58 \\
(8.9-15.4)\end{array}$ \\
\hline Brachytherapy & 224 (43.8) & $\begin{array}{c}202-246 \\
(39.5-48.1)\end{array}$ & $27(61.4)$ & $\begin{array}{c}21-33 \\
(46.6-74.3)\end{array}$ \\
\hline External beam & 286 (55.9) & $\begin{array}{c}264-308 \\
(51.5-60.1)\end{array}$ & $17(38.6)$ & $\begin{array}{c}11-23 \\
(25.7-53.4)\end{array}$ \\
\hline Unknown & $2(0.4)$ & $\begin{array}{c}0-7 \\
(0.0-1.4)\end{array}$ & $0(0)$ & $\begin{array}{c}0-4 \\
(0.0-8.0)\end{array}$ \\
\hline Surgery & $1363(48.0)$ & $\begin{array}{c}1311-1415 \\
(46.2-49.9)\end{array}$ & $226(60.3)$ & $\begin{array}{c}207-244 \\
(55.2-65.1)\end{array}$ \\
\hline Hormone therapy & $493(17.4)$ & $\begin{array}{c}455-534 \\
(16.0-18.8)\end{array}$ & $30(8.0)$ & $\begin{array}{c}21-42 \\
(5.7-11.2)\end{array}$ \\
\hline Active surveillance & $383(13.5)$ & $\begin{array}{c}349-420 \\
(12.3-14.8)\end{array}$ & $60(16.0)$ & $\begin{array}{c}47-75 \\
(12.6-20.1)\end{array}$ \\
\hline Chemo only & $2(0.0)$ & $\begin{array}{c}1-7 \\
(0.0-0.3)\end{array}$ & $0(0)$ & $\begin{array}{c}0-4 \\
(0.0-1.0)\end{array}$ \\
\hline Refused & $16(0.5)$ & $\begin{array}{c}10-26 \\
(0.3-0.9)\end{array}$ & $3(0.8)$ & $\begin{array}{c}1-9 \\
(0.3-2.3)\end{array}$ \\
\hline None & $41(1.4)$ & $\begin{array}{c}30-55 \\
(1.1-2.0)\end{array}$ & $9(2.4)$ & $\begin{array}{c}5-17 \\
(1.3-4.5)\end{array}$ \\
\hline Unknown & $28(1.0)$ & $\begin{array}{c}20-41 \\
(0.7-1.4)\end{array}$ & $3(0.8)$ & $\begin{array}{c}1-9 \\
(0.3-2.3)\end{array}$ \\
\hline
\end{tabular}

RAC: rapid access cancer clinic. 